\title{
The Investigation of Self-regulation and Language Learning Strategies
}

\author{
Tolga Erdogan \\ Army NCO Vocational College, National Defense University, Balikesir, Turkey
}

Copyright $\mathrm{O} 2018$ by authors, all rights reserved. Authors agree that this article remains permanently open access under the terms of the Creative Commons Attribution License 4.0 International License

\begin{abstract}
A body of research has shown that self-regulation and language learning strategies are important variables influencing learning. The aim of the study was to analyze the relationship between students' self-regulations and their language learning strategies. For research purposes, the correlations between self-regulations and language learning strategies and the changes according to achievement and grade level were examined. The participants comprised 860 higher education students attending various departments in a state university in Turkey. The Scale on Self-Regulation in Learning (SSRL) and Strategy Inventory for Language Learning (SILL) was used to gather data. Descriptive statistics, one-way MANOVA and correlation statistics were used during data analyses. The findings indicated medium positive correlations between the two main constructs and further provided evidence for changes in both student self-regulations and their language learning strategies based on achievement and grade level. Conclusions are drawn and suggestions for further practice and research are made in the end.
\end{abstract}

Keywords Self-regulation, Language Learning Strategies, Achievement, Grade Level, Higher Education

\section{Introduction}

Since the mid-1970s, there has been substantial growth in literature pertaining to language learning strategy (LLS) use. The growing number of publications have focused on the likely relationship between LLSs and several factors or outcomes such as achievement, proficiency level, nationality; motivation, beliefs about language learning, learning style, vocabulary size, goal orientations and cultural background etc. [1-16].

Despite this growing interest, the existing research has not been able to provide a link between the strategies students use in a language learning setting and their self-regulations in general. Up to date, comparatively few studies have examined self-regulation in language learning settings. For example, Kim et al. [8] investigated English language learners' self-efficacy profiles and their relationship with self-regulated learning (SRL) strategies. In another research, Ekhlasa and Shangarffam [17] examined the relationship that the determinant factors of self-regulation strategies have with main four language skills and overall proficiency. Having a notable paucity of research investigating the relationship between students' LLSs and their SRL levels, there is a need to study these two constructs more closely. Since LLSs and self-regulation are considered to contribute positively to student learning $[18,19]$, examining the link between them would offer researchers and practitioners some important insights into structuring the learning environment and helping students better.

\subsection{Literature Review}

\subsubsection{Language Learning Strategies and Self-regulation}

LLSs became popular in the field of language education in late 1970s. Since then many authors have tried to define and classify them. In her seminal work, Rubin [20] used the term learning strategies to mean "the techniques and devices which a learner may use to acquire knowledge" (p. 43). Later, Oxford [18] defined LLSs as "specific actions taken by the learner to make learning easier, faster, more enjoyable, more self-directed, more effective, and more transferrable to new situations" (p. 8). A quick review of related literature reveals different classifications or categorizations of LLSs. For research purposes, the author of the present study decided to use the taxonomy on LLSs offered by Oxford [18], where she divides them mainly into two: direct strategies and indirect strategies. In her taxonomy, direct strategies are memory, cognitive and compensation strategies. She labels metacognitive, affective and social strategies under indirect strategies. 
Self-regulation is one of the key concepts in Bandura's Social Learning Theory and is described by Zimmerman [21] as "self-generated thoughts, feelings, and actions that are planned and cyclically adapted to the attainment of personal goals" (p. 14). Successful learning involves "will" and "skill" of learners, both of which correspond to motivation and use of effective strategies inherent in self-regulation [22]. Thus, self-regulation not only encompasses cognitive skills, but also involves motivational factors such as self-efficacy, goal orientations, anxiety etc. Overall; academic self-regulated processes involve planning and time management; participation and concentration to instruction; organizing, recoding, and rehearsing the information, designing the study environment and using social sources effectively [23]. Additionally, in his review Schunk [24] lists some other self-regulated activities such as having aims and trying to realize those aims, believing in one's own capabilities, valuing learning, and having positive thoughts about anticipated outcomes of actions, and feeling of pride and satisfaction with one's own efforts.

\subsubsection{Studies on Language Learning Strategies and Self-regulation}

In the following sections research on LLSs and SRL is reviewed. The review mainly focuses on studies which have reported findings based on achievement and grade level.

Taking the proficiency levels of students, some research found positive correlations between level of proficiency and LLS use [25-27], while some others reported no relationships [28, 29]. Studies focusing on relationships between LLSs and achievement also had inconsistent results. Again, while some authors reported significant relationships between students' achievement levels and their LLS use [30-33], the others observed insignificant or no relationship at all $[15,34,35]$.

In his study with 368 university prep class students Cesur [32] aimed to explain and predict the relationship between Turkish university prep class students' LLSs and achievement in reading comprehension in a foreign language. The correlation and regression analysis results showed LLSs such as cognitive, memory and compensation predicted and had direct influence on the achievement in reading comprehension in a foreign language. Similarly, Sucu [33] found that high achievers in reading comprehension reported higher use of LLSs. In a recent study [30], successful students in vocabulary learning used the social and cognitive strategies more frequently than the less successful learners. With their study in a Chinese context Goh and Foong [5] concluded that metacognitive strategies were most frequently used, while memory strategies were used the least.

By administering Strategy Inventory for Language Learning (SILL) [18] to a total of $379(\mathrm{M}=87, \mathrm{~F}=292)$
English majors at Nanyang Institute of Technology in China, Liu [27] concluded that the most and the least frequently used strategies were metacognitive and memory strategies and that high proficient learners made use of the strategies more than their low proficient counterparts. The results of another study [36] with 502 students from three secondary schools in Hong Kong showed that the average strategy use fell in the medium range. Accordingly, the three most frequently used categorical strategies were compensative, metacognitive and affective. Although there was a positive relationship between duration of language exposure and LLS use, the differences were not significant.

In a study that investigated language learning strategies used by 418 EFL learners in Taiwan, Lai [26] observed that proficiency level had a significant effect on strategy choice and use. The conclusion was that more proficient learners used more learning strategies. They used metacognitive strategies and cognitive strategies most frequently and memory strategies the least; whereas the less proficient learners preferred social and memory strategies to cognitive and metacognitive strategies. Similarly, $\mathrm{Wu}$ [37] found that higher proficiency EFL students used learning strategies more often than lower proficiency EFL students, especially those cognitive, metacognitive and social strategies. On the other hand, no difference was observed in the use of memory strategies. Additionally, in a Turkish context with 140 undergraduates from a state university [38], the students were found high strategy users and the LLSs were widely used among more proficient learners than less proficient ones. Yilmaz observed that students favored the compensation strategies most and the affective strategies least.

The research examining the duration of study or influence of grade level in LLS preference has provided interesting findings. The recent study of Al-Natour [39] reported that fourth year (senior) students used LLSs significantly higher than the students in other levels. In another study [40], the results suggested that there was a positive relationship between LLS use and learning level (years of studying English). Conversely, in a recent study that investigated LLS used by Saudi EFL students $(\mathrm{N}=134)$ at Aljouf University, Alhaysony [41] found no significant difference in relation to duration of studying English, although students with long duration reported using LLSs more frequently.

Studies on self-regulation, on the other hand, have generally investigated the relationship self-regulation might have with different factors and examined the influence of self-regulation on some other dependent variables such as academic achievement. However, the results were mixed, inconsistent and inconclusive. For example, in some studies the effects of self-regulation on academic achievement were positive [42-46], whereas in some other research self-regulation didn't have any significant influence [47, 48]. Moreover, some evidence 
suggested that development of self-regulation took some time. In their longitudinal study with higher education students, Van der Hurk et al [49] found that students' self-regulation or self-regulatory learning skills developed significantly only in the third and fourth grades. Erdogan [45] added further evidence on the gradual development of SRL and identified that senior students' SRL levels were significantly higher than those attending their initial years in tertiary education.

Overall, these studies highlight the need for more research since the findings are far from univocal. The studies presented thus far provide insufficient evidence that both SRL and LLS might have an influence on students' achievements, proficiency levels and year of study or grade level. Though limited in number, some research has proposed evidence to the context-dependency of SRL [50, 51]. However, no previous study has given sufficient consideration to examine the interplay between SRL and LLS.

\subsection{Research Questions}

In this respect, the main purpose of the present study is to investigate the relationship between the SRL levels students have and the strategies they use in language learning settings. The research questions addressed in this paper include:

1. Are the SRL levels of students and their LLS use related?

2. Do students' self-regulations and their LLSs change through grades?

3. Are there differences between high and low achievers in terms of their SRL levels and LLSs?

It is hypothesized that students' SRL and LLS levels might be linked to each other. In other words, the students are expected to resort to LLSs more depending on their level of self-regulation. Having such an intimate relationship, the changes in students' LLS preferences and self-regulations are expected to show similarities based on students' achievement and grade levels.

\section{Method}

\subsection{Participants and Sampling}

In this exploratory study, the participants were higher education students studying at various departments in a state university in Turkey. By using cluster and convenience sampling together, research instruments were given to 1,043 students who were taking English as a foreign language courses through all grades (from freshmen to seniors). A total of 860 students (1st grade $=237,2 \mathrm{nd}=194$, 3rd $\operatorname{grade}=213$, 4th $\operatorname{grade}=216$ ) completed the instruments with a return rate of $82.5 \%$.

\subsection{Instruments}

The study was conducted in the form of a survey, with data being gathered via "Scale on Self-Regulation in Learning-SSRL" and "Strategy Inventory for Language Learning-SILL". The 67-item SSRL [52] has two subscales, self-regulated learning skills/strategies (45 items) and motivational factors (22 items). The SILL [18] consists of 50 items under two main constructs of direct (29 items) and indirect (21 items) learning strategies, with three categories under each subscale. In the present study, the alpha coefficients for both SSRL and SILL were computed as .91. The sub-categories and factors of each scale and their equivalent Alpha coefficients found for the present sample are shown in Table 1.

\subsection{Procedures and Data Analysis}

Both instruments were given separately to the same students with one week interval between the two administrations. Grant of application was received from the Board of Ethics. Help was given by the faculty during scale applications, administrations of which took 20-25 minutes each. Statistical analyses were performed using SPSS software (version 20). Descriptive statistics, one-way MANOVA and correlation statistics were used for analysis purposes. 
Table 1. The Sub-categories and Factors of SSRL and SILL

\begin{tabular}{|c|c|c|c|c|c|c|c|c|c|}
\hline \multicolumn{5}{|c|}{$\begin{array}{l}\text { Scale on Self-Regulation in Learning } \\
\text { (SSRL) }(\alpha=.91)\end{array}$} & \multicolumn{5}{|c|}{$\begin{array}{c}\text { Strategy Inventory for Language Learning } \\
\text { (SILL) }(\alpha=.91)\end{array}$} \\
\hline Self-regulated Learning Skills & & \multicolumn{2}{|c|}{ Motivational Factors } & & Direct Strateg & \multicolumn{4}{|c|}{ Indirect Strategies } \\
\hline $\begin{array}{l}\text { Arrangement of study time } \\
\text { Planning } \\
\text { Environmental structuring } \\
\text { Organization and transforming } \\
\text { Seeking appropriate information } \\
\text { Seeking easily accessible information } \\
\text { Rehearsing and memorizing } \\
\text { Self-monitoring } \\
\text { Seeking peer, teacher or adult assistance } \\
\text { Self-evaluation } \\
\text { Self-consequences after success } \\
\text { Self-consequences after failure } \\
(\alpha=.89)\end{array}$ & & \multicolumn{2}{|c|}{$\begin{array}{l}\text { Self-efficacy } \\
\text { Goal-orientations } \\
\text { Task value } \\
\text { Attributions for failure } \\
\text { Anxiety } \\
(\alpha=.81)\end{array}$} & & \multicolumn{2}{|c|}{$\begin{array}{l}\text { Memory strategies } \\
\text { Cognitive strategies } \\
\text { Compensation strategies } \\
(\alpha=.85)\end{array}$} & \multicolumn{2}{|c|}{$\begin{array}{l}\text { Metacognitive strategies } \\
\text { Affective Strategies } \\
\text { Social strategies } \\
(\alpha=.85)\end{array}$} & \\
\hline & SSRL Skills & $\begin{array}{c}\text { SSRL } \\
\text { Motivation }\end{array}$ & SILL Entire & $\begin{array}{l}\text { SILL Memory } \\
\text { Strategies }\end{array}$ & $\begin{array}{c}\text { SILL } \\
\text { Cognitive } \\
\text { Strategies }\end{array}$ & $\begin{array}{c}\text { SILL } \\
\text { Compensation } \\
\text { Strategies }\end{array}$ & $\begin{array}{c}\text { SILL } \\
\text { Metacognitive } \\
\text { Strategies }\end{array}$ & $\begin{array}{l}\text { SILL Affective } \\
\text { Strategies }\end{array}$ & $\begin{array}{l}\text { SILL Social } \\
\text { Strategies }\end{array}$ \\
\hline SSRL Entire &, $939^{* *}$ &, $757^{* *}$ &, $533^{* *}$ &, $411^{* *}$ &, $466^{* *}$ &, $257^{* *}$ &, $501^{* *}$ &, $269^{* *}$ &, $403^{* *}$ \\
\hline SSRL Skills & &, $487^{* *}$ &, $542^{* *}$ &, $438^{* *}$ &, $453^{* *}$ &, $251^{* *}$ &, $495^{* *}$ &, $304^{* *}$ &, $433^{* *}$ \\
\hline SSRL Motivation & & &, $325^{* *}$ &, $213^{* *}$ &, $323^{* *}$ &, $176^{* *}$ &, $333^{* *}$ &, $107^{* *}$ &, $201^{* *}$ \\
\hline SILL Entire & & & &, $733^{* *}$ &, $894^{* *}$ &, $631^{* *}$ &, $815^{* *}$ &, $621^{* *}$ &, $695^{* *}$ \\
\hline SILL Memory Strategies & & & & &, $585^{* *}$ &, $366^{* *}$ &, $477^{* *}$ &, $460^{* *}$ &, $414^{* *}$ \\
\hline SILL Cognitive Strategies & & & & & &, $544^{* *}$ &, $691^{* *}$ &, $425^{* *}$ &, $531^{* *}$ \\
\hline SILL Compensation Strategies & & & & & & &, $424^{* *}$ &, $243^{* *}$ &, $337^{* *}$ \\
\hline SILL Metacognitive Strategies & & & & & & & &, $391^{* *}$ &, $455^{* *}$ \\
\hline SILL Affective Strategies & & & & & & & & &, $428^{* *}$ \\
\hline
\end{tabular}

**. Correlation is significant at the 0.01 level (2-tailed) 


\section{Results and Discussion}

Findings and related comments for each research question are given below separately.

\subsection{Research Question 1}

Based on data obtained from SSRL and SILL scores, as shown in Table 2, there is a positive medium correlation (.53) between the two inventories as a whole. Similar positive significant correlations are also true for the subscales. The correlations between the entire inventory and subscales of both SSRL and SILL range from .54 to .11, where the strongest correlation seems to exist between SSRL Skills and SILL Entire and the lowest correlation is between SSRL Motivational Factors and SILL Affective Strategies. These results might indicate that language learning strategies and self-regulation, both measured with self-report inventories, are intertwined. Nevertheless, these correlations tell us nothing about the direction of causality. Hence, we cannot suggest that frequency of language learning strategies is attributable to specific aspects of self-regulation or vice versa.

It is quite arguable that such medium positive correlations between these two constructs are predictable due to similar items or factors they share. That may be true to some extent. When the inventories are analyzed thoroughly, it is easy to see that both contain similar items, e.g. metacognitive, compensation, social and affective strategies or skills. However, the point here is a matter of context. SSRL aims to measure students' general behaviors of self-regulation, hence it is considered context general; whereas SILL, a context specific measure, identifies students' strategies or skills in foreign/second language learning only. Thus, the finding in the present study might show the variance and/or relationships in students' levels of learning skills or strategies in a general and specific context. Thus, it can be concluded that students' learning behaviors in a general and a specific context show medium level congruence.

\subsection{Research Question 2}

Related to this question the descriptive statistics are presented in Table 3. A Shapiro-Wilk's test $(p>.05)$ and a visual inspection of the histograms and box plots showed that the scores for the samples were approximately normally distributed. A Levene's test verified the equality of variances in the samples (homogeneity of variance) $(p>.05)[53]$.

To investigate the differences in students' self-regulations and language learning strategies through grades (from freshmen to seniors), a one way between groups multivariate analysis of variance (MANOVA) was performed. Three dependent variables from SSRL (SSRL Entire, SSRL Skills and SSRL Motivation) and seven dependent variables from SILL (SILL Entire and the six strategies of memory, cognitive, compensation, metacognitive, affective and social) were used. The independent variables were students' grade levels (freshmen to seniors).

Considering the self-regulation levels of students, there was a statistically significant difference between grade levels on the combined dependent variables: $F$ (6, $1710.000)=5.20, p<0.001$; Wilk's Lambda $=0.96$, partial eta squared $=0.018$. When the results for the whole inventory and subscales of SSRL were considered separately, there was a significant difference $(p<0.05)$ among the mean scores received through grades 1-4: SSRL Entire, F (3, $856)=9.72, p>0.05$, partial eta squared $=0.033$; SSRL Skills, $\mathrm{F}(3,856)=7.25, p>0.05$, partial eta squared $=0.025$; SSRL Motivation, $\mathrm{F}(3,856)=7.92, \quad p>0.05$, partial eta squared $=0.027$. According to significant grade level pair wise differences obtained; SSRL Entire mean scores of seniors were higher than those of freshmen and sophomores, while the mean scores of juniors were higher than only the mean scores of freshmen. SSRL Skills and Motivation mean scores of seniors were significantly higher than the mean scores of freshmen and sophomores $(p<0.05)$. Overall, these findings confirm the gradual increase in students' SRL levels.

Table 3. Descriptive Statistics Obtained for SSRL and SILL

\begin{tabular}{|c|c|c|c|c|c|c|c|c|c|}
\hline Scale/Subscale & Grade & $\mathrm{n}$ & $\mathrm{M}$ & sd & Scale/Subscale & Grade & $\mathrm{n}$ & $\mathrm{M}$ & sd \\
\hline \multirow{4}{*}{ SSRL Entire } & $1 \mathrm{ST}$ & 237 & 207,83 & 28,92 & \multirow{4}{*}{ SILL Cognitive Strategies } & $1 \mathrm{ST}$ & 237 & 42,23 & 8,06 \\
\hline & 2ND & 194 & 211,32 & 30,09 & & $2 \mathrm{ND}$ & 194 & 42,56 & 8,90 \\
\hline & $3 \mathrm{RD}$ & 213 & 216,01 & 29,50 & & $3 R D$ & 213 & 42,10 & 8,52 \\
\hline & $4 \mathrm{TH}$ & 216 & 222,19 & 30,39 & & $4 \mathrm{TH}$ & 216 & 43,93 & 8,44 \\
\hline \multirow{4}{*}{ SSRL Skills } & $1 \mathrm{ST}$ & 237 & 136,79 & 21,85 & \multirow{4}{*}{ SILL Compensation Strategies } & $1 \mathrm{ST}$ & 237 & 19,70 & 3,87 \\
\hline & $2 \mathrm{ND}$ & 194 & 139,69 & 23,19 & & $2 \mathrm{ND}$ & 194 & 20,11 & 4,10 \\
\hline & $3 R D$ & 213 & 142,08 & 22,92 & & $3 R D$ & 213 & 20,24 & 4,07 \\
\hline & $4 \mathrm{TH}$ & 216 & 146,30 & 21,38 & & $4 \mathrm{TH}$ & 216 & 19,87 & 3,81 \\
\hline \multirow{4}{*}{ SSRL Motivation } & $1 \mathrm{ST}$ & 237 & 71,04 & 11,57 & \multirow{4}{*}{ SILL Metacognitive Strategies } & $1 \mathrm{ST}$ & 237 & 29,52 & 6,27 \\
\hline & 2ND & 194 & 71,64 & 11,73 & & $2 \mathrm{ND}$ & 194 & 28,54 & 7,67 \\
\hline & 3RD & 213 & 73,92 & 11,24 & & $3 \mathrm{RD}$ & 213 & 28,62 & 6,36 \\
\hline & $4 \mathrm{TH}$ & 216 & 75,90 & 12,27 & & $4 \mathrm{TH}$ & 216 & 31,08 & 6,45 \\
\hline \multirow{4}{*}{ SILL Entire } & $1 \mathrm{ST}$ & 237 & 149,90 & 23,22 & \multirow{4}{*}{ SILL Affective Strategies } & $1 \mathrm{ST}$ & 237 & 15,45 & 4,32 \\
\hline & 2ND & 194 & 150,77 & 28,20 & & $2 \mathrm{ND}$ & 194 & 15,64 & 4,03 \\
\hline & $3 R D$ & 213 & 150,53 & 24,36 & & $3 R D$ & 213 & 15,24 & 3,76 \\
\hline & $4 \mathrm{TH}$ & 216 & 157,13 & 23,78 & & $4 \mathrm{TH}$ & 216 & 16,50 & 4,30 \\
\hline \multirow{4}{*}{ SILL Memory Strategies } & $1 \mathrm{ST}$ & 237 & 26,00 & 4,84 & \multirow{4}{*}{ SILL Social Strategies } & $1 \mathrm{ST}$ & 237 & 16,00 & 4,88 \\
\hline & $2 \mathrm{ND}$ & 194 & 26,61 & 5,38 & & $2 \mathrm{ND}$ & 194 & 17,30 & 4,85 \\
\hline & $3 R D$ & 213 & 26,55 & 5,11 & & $3 R D$ & 213 & 17,77 & 4,45 \\
\hline & $4 \mathrm{TH}$ & 216 & 27,13 & 4,34 & & $4 \mathrm{TH}$ & 216 & 18,63 & 4,29 \\
\hline
\end{tabular}


When the results for the entire inventory and subscales of SILL were considered, there was a statistically significant difference among grade levels on the combined dependent variables: $\mathrm{F}(18,2407.477)=2.91, p<0.001$; Wilk's Lambda $=0.94$, partial eta squared $=0.020$. When the results for the dependent variables were considered separately, there were statistically significant differences $(p<0.05)$ in entire SILL mean scores and in indirect strategies of metacognitive, affective and social strategies. Pair wise post hoc analyses showed that; SILL Entire mean scores of seniors $(\mathrm{M}=157.13)$ were significantly higher than the mean scores of freshmen $(\mathrm{M}=149.90)$; Metacognitive Strategies mean scores of seniors $(M=31.08)$ were significantly higher than those of sophomores $(\mathrm{M}=28.54)$ and juniors $(\mathrm{M}=28.62)$; Affective Strategies mean scores of seniors $(M=16.50)$ were higher than the mean scores of freshmen $(\mathrm{M}=15.45)$; Social Strategies mean scores of seniors $(M=18.63)$ were significantly higher than the mean scores of freshmen $(\mathrm{M}=16.00)$ and sophomores $(\mathrm{M}=17.30)$.

According to the findings, it can be asserted that both SSRL and SILL mean scores increased through grade levels. The results seem to be consistent with those in the literature [39, 40, 45, 49]. However, it is important to consider that while there was a steady increase in SSRL Entire and subscale mean scores through grades, no changes were observed from freshmen to seniors in SILL Direct Strategies of Memory, Cognitive and Compensation. This finding might point out to the lack of language strategy use and a further need for overt learning strategy instruction in foreign language teaching.

\subsection{Research Question 3}

In order to find the answer to this question, students were ranked according to their achievement grades in English as a Foreign Language course. Later the top and the bottom quartiles $(\mathrm{n}=215)$ were selected and labeled as high and low achievers. The grades of high achievers range from 81 to 100 (out of 100) and those of low achievers range from 35 to 59 . Table 4 shows the descriptive statistics of the scores those high and low achievers received from the entire inventory and subscales of SSRL and SILL.

To investigate the differences in students' self-regulations and language learning strategies based on their achievement levels, a one way between groups multivariate analysis of variance (MANOVA) was performed. Three dependent variables from SSRL (SSRL Total, SSRL Skills and SSRL Motivation) and seven dependent variables from SILL (SILL Total, and the six strategies of memory, cognitive, compensation, metacognitive, affective and social) were used. The independent variables were students' achievement levels (high and low achievers).

Considering the self-regulation levels of students, there was a statistically significant difference between high and low achievers on the combined dependent variables: F (2, 427.000) $=13.94, p<0.001$; Wilk's Lambda $=0.94$, partial eta squared $=0.061$. When the results for the entire inventory and subscales of SSRL were considered separately, there was a statistically significant difference $(p<0.05)$ between the mean scores received by high and low achievers. High achievers scored higher than low achievers in the entire inventory and subscales of SSRL.

When the results for the entire inventory and subscales of SILL were considered, there was a statistically significant difference between high and low achievers on the combined dependent variables: $F(6,423.000)=22.99$, $p<0.001$; Wilk's Lambda $=0.75$, partial eta squared $=0.246$. When the results for the entire inventory and subscales of SILL were considered separately, there was a significant difference $(p<0.01)$ in entire inventory and subscale mean scores of SILL; except for SILL Affective Strategies, F (1, $428)=0.06, p>0.05$, partial eta squared $=0.000$ and SILL Social Strategies, F $(1,428)=1.72, p>0.05$, partial eta squared $=0.004$, in which no significant difference was detected.

Table 4. Descriptive Statistics Based on Achievement (High vs Low)

\begin{tabular}{ccccccc}
\hline \multirow{2}{*}{ Scale/Subscale } & \multicolumn{3}{c}{ High Achievers } & \multicolumn{3}{c}{ Low Achievers } \\
\cline { 2 - 7 } & $\mathrm{n}$ & $\mathrm{M}$ & $\mathrm{sd}$ & $\mathrm{n}$ & $\mathrm{M}$ & $\mathrm{sd}$ \\
\hline SSRL Entire & 215 & 224,24 & 30,56 & 215 & 210,50 & 29,89 \\
SSRL Skills & 215 & 147,16 & 23,07 & 215 & 139,50 & 21,28 \\
SSRL Motivation & 215 & 77,08 & 12,14 & 215 & 71,00 & 12,33 \\
SILL Entire & 215 & 163,04 & 24,01 & 215 & 145,96 & 23,77 \\
SILL Memory & 215 & 28,18 & 5,32 & 215 & 25,86 & 4,57 \\
SILL Cognitive & 215 & 46,30 & 8,08 & 215 & 40,20 & 8,38 \\
SILL Compensation & 215 & 21,58 & 3,85 & 215 & 18,54 & 3,66 \\
SILL Metacognitive & 215 & 32,63 & 6,62 & 215 & 27,47 & 6,04 \\
SILL Affective & 215 & 16,08 & 3,96 & 215 & 16,17 & 3,78 \\
SILL Social & 215 & 18,27 & 4,18 & 215 & 17,72 & 4,57 \\
\hline
\end{tabular}


The aforementioned findings indicate the existence of difference between high and low achievers in terms of their self-regulation levels and LLS use. Consistent with existing research [42-46], the high achieving students' SRL levels differed significantly than those of low achievers. Taking LLS use, in overall, the high achieving students seem to resort more to the learning strategies than their low achieving counterparts. This also accords with earlier observations [30-33], which reported significant relationships between students' achievement levels and their LLS use. However, it was surprising that high achievers did not differ significantly from the low achievers in Affective and Social strategies. It seems possible to reflect that students in high and low achieving groups used the affective and social strategies at the same level.

\section{Limitations and Directions for Further Research and Practice}

The present study yields some preliminary findings; however there are some limitations, which also point out directions for future research. First, it is important to acknowledge that self-report instruments were used to measure students' levels of self-regulation and strategy use hence their actual behavior was not assessed. Second, the findings in the present study should be approached carefully since they were based on a sample of Turkish students, cultural and educational experience of whom may have particular influence on their self-regulation levels and learning strategies in a foreign language setting. Finally, it is important to note that the participating students didn't have any overt language strategy use instruction or training on self-regulation. The existing literature on strategy instruction $[54,55]$ confirms the positive and significant effects of such training not only on frequency of learning strategy use, but also on other learning outcomes such as achievement. Zimmerman [23] also postulated that direct or indirect training of self-regulated learning could give better results in terms of achievement. So, it is believed that repetition of this study with groups having explicit language strategy use instruction or training on self-regulation would reveal different results.

As a final word, the findings of this study could be used to individualize classroom instruction based on students' levels of LLS use and SRL and further research could investigate the results of the interventions. Another subsequent study would be to analyze the relationship between students' SRL levels and the learning strategies they employ in other disciplines such as math, science, literature, history, etc. and compare the results with the findings of the present study.

\section{Conclusions}

This exploratory study used quantitative data from two scale applications to investigate the relationship between students' SRL levels and their LLS use. Further, this research set out to examine the differences in students' SRL levels and LLS use by taking grade level and achievement as basis. The results of the present study confirmed the existence of a moderately intimate relationship between students' levels of SRL and their LLS use. Considering students' year of study, both self-regulation levels and LLS use increased through grade levels. However, no changes were observed from freshmen to seniors in SILL Direct Strategies of Memory, Cognitive and Compensation. The results further showed that the SSRL and the SILL identified differences between high and low achievers. As hypothesized, high achieving students' SRL levels differed significantly than those of low achievers. There was also a significant difference in entire inventory and subscale mean scores of SILL, except for Affective Strategies and Social Strategies.

In conclusion; given that the previous and present research suggest mixed findings on factors like year of study and achievement, there is a need for more research to explore the relationship between learners' self-regulations and their learning strategies in a foreign language learning setting.

\section{REFERENCES}

[1] Bremner, S. (1999). Language learning strategies and language proficiency: investigating the relationship in Hong Kong. Canadian Modern Language Review, 55(4), 490-514.

[2] Chang, C. H., \& Liu, H. J. (2013). Language learning strategy use and language learning motivation of Taiwanese EFL university students. Electronic Journal of Foreign Language Teaching, 10(2), 196-209.

[3] Chen, M. L. (2009). Influence of grade level on perceptual learning style preferences and language learning strategies of Taiwanese English as a foreign language learners. Learning and Individual Differences, 19(2), 304-308.

[4] Diseth, Á. (2011). Self-efficacy, goal orientations and learning strategies as mediators between preceding and subsequent academic achievement. Learning and Individual Differences, 21(2), 191-195.

[5] Goh, C., \& Foong, K. P. (1997). Chinese ESL students' learning strategies: A look at frequency, proficiency and gender. Hong Kong Journal of Applied Linguistics, 2(1), 3953.

[6] Grainger, P. (2012). The impact of cultural background on the choice of language learning strategies in the JFL context. System, 40(4), 483-493.

[7] Griffiths, C. (2003). Patterns of language learning strategy use. System, 31(3), 367-383.

[8] Kim, D. H., Wang, C., Ahn, H. S., \& Bong, M. (2015). English language learners' self-efficacy profiles and relationship with self-regulated learning strategies. Learning 
and Individual Differences, 38, 136-142.

[9] Magogwe, J. M., \& Oliver, R. (2007). The relationship between language learning strategies, proficiency, age and self-efficacy beliefs: A study of language learners in Botswana. System, 35(3), 338-352.

[10] Nacera, A. (2010). Languages learning strategies and the vocabulary size. Procedia Social and Behavioral Sciences, 2, 4021-4025.

[11] Nasihah, M., \& Cahyono, B. Y. (2017). Language learning strategies, motivation, and writing achievement of Indonesian EFL students. Arab World English Journal, 8(1), 250-263.

[12] Phan, H. P. (2009). Exploring students' reflective thinking practice, deep processing strategies, effort, and achievement goal orientations. Educational Psychology, 29(3), 297-313.

[13] Shmais, W. A. (2003). Language learning strategy use in Palestine. TESL-EJ, 7(2), 1-17.

[14] Wong, L. L. C., \& Nunan, D. (2011). The learning styles and strategies of effective language learners. System, 39(2), 144-163.

[15] Yalçın, E. (2003). An analysis of the relationship between the use of grammar learning strategies and student achievement at English preparatory school at the University of Gaziantep (A case study of the Gaziantep University). (Unpublished Master's Dissertation). Gaziantep University, Gaziantep, Turkey.

[16] Zare-ee, A. (2010). Associations between university students' beliefs and their learning strategy use. Procedia Social and Behavioral Sciences, 5, 882-886.

[17] Ekhlasa, N. N., \& Shangarffam, N. (2013). The relationship between determinant factors of self-regulation strategies and main language skills and overall proficiency. Procedia Social and Behavioral Sciences, 70, 137-147.

[18] Oxford, R. (1990). Language learning strategies: What every teacher should know. Boston: Heinle and Heinle Publishers.

[19] Zimmerman, B. J., \& Schunk, D. H. (2001). Self-regulated learning and academic achievement: Theoretical perspectives. New York: Lawrence Erlbaum Associates, 2. Edition.

[20] Rubin, J. (1975). What the 'good language learner' can teach us. TESOL Quarterly, 9(1), 41-51.

[21] Zimmerman BJ (2000) Attaining self-regulation: A social cognitive perspective. In Boekaerts M, Pintrich PR, Zeidner $\mathrm{M}$ (eds.) Handbook of Self-Regulation (pp. 13-39). Academic Press, New York.

[22] Pintrich, P. R., \& De Groot, E. V. (1990). Motivational and self-regulated learning components of classroom academic performance. Journal of Educational Psychology, 82(1), $33-40$.

[23] Zimmerman, B. J. (1990). Self-regulated learning and academic achievement: An overview. Educational Psychologist, 25(1), 3-17.

[24] Schunk, D. H. (1994). Self-Regulation of Self-Efficacy and Attributions in Academic Settings. In Dale H. Schunk and
Barry J. Zimmerman (Eds) Self-Regulation of Learning and Performance: Issues and Educational Applications ( pp. 75-99). Hillsdale, NJ: Lawrence Erlbaum Associates, Publishers.

[25] Karahan, B. (1991). An investigation into learning strategies used by beginning and intermediate level students learning English as a foreign language. (Unpublished doctoral dissertation). Gazi University, Ankara, Turkey.

[26] Lai, Y.C. (2009). Language learning strategy use and English proficiency of university freshmen in Taiwan. TESOL Quarterly, 43(2), 255-280.

[27] Liu, D. (2004). EFL proficiency, gender and language learning strategy use among a group of Chinese technological institute English majors. ARECLS E-Journal, 1(A5). (Retrieved on January, 15, 2017).

[28] Çavuşoğlu, İ. (1992). The relationship between language learning strategies and EFL proficiency. (Unpublished Master's Dissertation), Bosphorus University, Istanbul, Turkey.

[29] Tüz, H. F. (1995). The use of learning strategies by the "more successful" and "less successful" language learners. (Unpublished Master's Dissertation). Middle East Technical University, Ankara, Turkey.

[30] Alamdari, S. Z. (2010). The relationship between vocabulary learning strategies employed by university level English language learners and their success. (Unpublished Master's Dissertation). Hacettepe University, Ankara, Turkey.

[31] Aydemir, U. V. (2007). Effects of the instruction of language learning strategies on students' achievement in English teaching. (Unpublished Master's Dissertation). Uludağ University, Bursa, Turkey.

[32] Cesur, M. O. (2011). Can language learning strategies predict Turkish university prep class students' achievement in reading comprehension? Procedia Social and Behavioral Sciences 15, 1920-1924.

[33] Sucu, H.Ö. (2009). Contributions of metacognitive learning strategies to the development of reading comprehension in foreign language teaching and metacognitive strategy instruction (Nevsehir University sample). (Unpublished Master's Dissertation). Erciyes University, Kayseri, Turkey.

[34] Murray, B. (2007). Metacognitive strategies and the achievement of listening proficiency in the language classroom. Korean Journal of Applied Linguistics, 23(1), 115 .

[35] Song, X. (2005). Language learner strategy use and English proficiency on the Michigan English language assessment battery. Spaan Fellow Working Papers in Second or Foreign Language Assessment, 3, 1-26.

[36] Leung, Y. \& Hui, A. (2011). Language learning strategy of Hong Kong Putonghua learners. Educational Research Journal, 26(1), 17-38.

[37] Wu, Y. L. (2008). Language learning strategies used by students at different proficiency levels. Asian EFL Journal, 10(4), 75-95.

[38] Y1lmaz, C. (2010). The relationship between language learning strategies, gender, proficiency and self-efficacy beliefs: a study of ELT learners in Turkey. Procedia Social 
and Behavioral Sciences, 2, 682-687.

[39] Al-Natour, A. (2012). The most frequently used language learning strategies by Jordanian university students at Yarmouk university that affect EFL learning. European Journal of Social Sciences 29(4), 528-536.

[40] Al-Buainain, H. (2010). Language learning strategies employed by English majors at Qatar University: Questions and queries. ASIATIC, 4(2), 92-120.

[41] Alhaysony, M. (2017). Language learning strategies use by Saudi EFL students: The effect of duration of English language study and gender. Theory and Practice in Language Studies, 7(1), 18-28.

[42] Camahalan, F. M. (2006). Effect of self-regulated learning on mathematics achievement of selected Southeast Asian children. Journal of Instructional Psychology, 33(3), 194-205.

[43] Cekolin, C. H. (2001). The effect of self-regulated learning strategy instruction on strategy use and academic achievement. (Unpublished doctoral dissertation). University of South Alabama. UMI: 9999814.

[44] Douglas, L. B. (2006). A Multivariate Analysis of the Relationship between Age, Self-Regulated Learning, and Academic Performance among Community College Developmental Education Student. (Unpublished doctoral dissertation). Touro University International. UMI: 3201703 .

[45] Erdogan, T. (2011). Self-regulation and its effects on academic achievement. TMA Science Journal, 21(2), $127-146$.

[46] Staudt, L. E. (1995). Self-regulated learning strategies: Their relation to academic performance and self-efficacy in Chemistry and English. (Unpublished Master's Dissertation). Windsor University, Canada.
[47] Heo, H. (1998). The effect of self-regulated learning strategies on learner achievement perceptions on personal learning responsibility. (Unpublished doctoral dissertation). Florida State University. UMI: 9911444.

[48] Lewis, J. P. (2006). Effects of self-regulated learning on metacognitive strategies, academic performance, and transfer of preservice teachers in an educational technology class. (Unpublished doctoral dissertation). University of South Alabama. UMI: 3209436.

[49] Van den Hurk, M. M., Wolfhagen, I. H. A. P., Dolmans, D. J. H. M., \& Van der Vleuten, C. P. M. (1999). The impact of student-generated learning issues on individual study time and academic achievement. Medical Education, 33(11), 808-814.

[50] Rotgans, J., \& Schmidt, H. (2009). Examination of the context-specific nature of self-regulated learning. Educational Studies, 35(3), 239-253.

[51] Vermetten, Y. J., Lodewijks, H. G., \& Vermunt, J. D. (1999). Consistency and variability of learning strategies in different university courses. Higher Education, 37(1), 1-21.

[52] Erdogan, T., \& Senemoglu, N. (2016). Development and validation of a scale on self-regulation in learning (SSRL). SpringerPlus 5(1686), 1-13.

[53] Martin, W. E., \& Bridgmon, K. D. (2012). Quantitative and statistical research methods: From hypothesis to results. Somerset, NJ: Wiley.

[54] Cohen, A. D., \& Weaver, S. J. (1998). Strategies-based instruction for second language learners. In Renandya, W. A. \& Jacobs, G. M. (eds.) Learners and language learning. Singapore: SEAMEO Regional Language Centre, 1-25.

[55] Dreyer, C., \& Nel, C. (2003). Teaching reading strategies and reading comprehension within a technology-enhanced learning environment. System, 31(3), 349-365. 